\section{Análisis de laboratorio para el diagnóstico temprano de insuficiencia renal crónica}

López-Heydeck SM, ${ }^{1}$ López-Arriaga JA, ${ }^{2}$ Montenegro-Morales LP, ${ }^{3}$ CereceroAguirre $\mathrm{P}^{3}$ Vázquez-de Anda GF ${ }^{3}$

\section{Resumen}

La detección temprana de una insuficiencia renal crónica (IRC), permite prolongar la vida funcional de los riñones, disminuir los casos de diálisis y el riesgo de muerte por enfermedad cardiovascular. Las pruebas de diagnóstico de oro son, para daño renal, proteinuria en orina de 24 horas y para función renal, el filtrado glomerular con marcadores externos; estas son utilizadas solo a indicios o riesgo de enfermedad renal, y son imprácticas para estudios epidemiológicos, por lo que resulta más práctico el utilizar el índice del filtrado glomerular estimado (IFGe), con una ecuación para marcadores internos, como es creatinina, cuyo valor se ve influenciado por ingesta de creatina, producción de creatinina y masa muscular, pero dicho efecto es aminorado por estas ecuaciones, pero, al haber también variaciones según el método de laboratorio y entre laboratorios, las más recientes ecuaciones requieren valores de creatinina estandarizados al método de referencia internacional espectrometría de masas por dilución isotópica, el cual solo se ha establecido en algunos países y en menos países todo valor de creatinina se da junto con el valor del IFGe y pocos países aplican el índice de la relación proteína-creatinina en una sola toma de muestra de orina", del inglés "spot urine proteincreatinine ratio"

PALABRAS CLAVE: Enfermedad renal crónica; detección temprana; Proteinuria; Tasa de filtración glomerular; Proteína-creatinina en muestras de orina.

Rev Mex Urol. 2018 Jan-Feb;78(1):73-90.

\section{Laboratory analyses for early diagnosis of chronic kidney disease}

López-Heydeck SM, ${ }^{1}$ López-Arriaga JA, ${ }^{2}$ Montenegro-Morales LP, ${ }^{3}$ CereceroAguirre $\mathrm{P}^{3}$ Vázquez-de Anda $\mathrm{GF}^{3}$

\section{Abstract}

EARLY detection of chronic kidney disease enables longer kidney function, reduces the cases of dialysis, and lowers the risk of death

\footnotetext{
${ }^{1}$ Departamento de Investigación, asistente de Investigación

${ }^{2}$ Coordinador, profesor e investigador

${ }^{3}$ Departamento de Investigación, profesor e investigador

Universidad Autónoma del Estado de México, Centro de Investigación en Ciencias Médicas, Toluca de Lerdo, México.
}

Recibido: agosto 2017

Aceptado: noviembre 2017

Correspondencia

Sandra Maricruz López Heydeck

heydeck@hotmail.com

Este artículo debe citarse como

López-Heydeck SM, López-Arriaga JA, MontenegroMorales LP, Cerecero-Aguirre P, Vázquez-de Anda GF. Análisis de laboratorio para el diagnóstico temprano de insuficiencia renal crónica. Rev Mex Urol. 2018 ene-feb;78(1):73-90. DOI: https://doi.org/10.24245/revmexurol.v78i1.1601 


\begin{abstract}
from cardiovascular disease. The standard diagnostic tests for kidney damage and kidney function are the 24-h urine protein test and glomerular filtration rate with external markers, respectively, but they are used only when there are signs of or risk for kidney disease and are impractical for epidemiologic studies. A more practical test is the estimated glomerular filtration rate, with an equation for internal markers, such as creatinine. The serum creatinine value is influenced by creatine ingestion, creatinine production, and muscle mass, but their effect is decreased through those equations. To reduce interlaboratory variation in creatinine assay calibration, the estimated glomerular filtration rate should be calculated from serum creatinine using an equation that is traceable to isotope dilution mass spectrometry. This has been established in many countries, but some give all creatinine values together with only the estimated glomerular filtration rate, and a limited number of countries apply the spot urine protein/creatinine ratio.
\end{abstract}

KEYWORDS: Chronic kidney disease; Early detection; Proteinuria; Glomerular filtration rate; Urine protein creatinine.

\section{ANTECEDENTES}

La función de los riñones es mantener el equilibrio fisiológico del individuo; su afectación altera, principalmente, los sistemas circulatorio y óseo (o viceversa), ${ }^{1}$ debido a la relación de sus funciones de filtración, equilibrio electrolítico, producción de hormonas y desecho de sustancias, iniciando en el sistema de capilares incluidos en cada unidad funcional: la nefrona (glomérulo, el túbulo contorneado proximal, el asa de Henle y el túbulo contorneado distal que termina en un conducto colector) $)^{2}$ es donde más se llevan a cabo estas funciones que algunas ocasiones son afectadas o destruidas por la acción lacerante de procesos como: diabetes o hipertensión (entre las más importantes); inflamación por enfermedades autoinmunitarias o infecciosas; agentes tóxicos, principalmente medicamentos (antiinflamatorios no esteroides y aminoglucósidos); procesos mecánicos provocados por parásitos, excesiva formación de cristales que originan cálculos renales o el incremento de la presión en los conductos debido a cierta obstrucción interna o externa de la vía urinaria inferior, ya sea por diversos tipos de inflamación, tumores internos o externos, cálculos, incluso por alteraciones genéticas (riñón poliquístico) o cáncer renal.

Cuando esto sucede puede manifestarse como daño renal y provocar alguna enfermedad relacionada o insuficiencia renal aguda o crónica temprana, con evolución a insuficiencia renal crónica terminal, diálisis y muerte. ${ }^{1}$ Desgraciadamente pasa mucho tiempo sin ser clínicamente perceptible la disminución del número de nefronas funcionales. En la mayoría de los casos se detecta tardíamente, cuando la pérdida es grave y se establece el diagnóstico de insuficiencia renal terminal, o poco antes, lo que resulta en muerte por enfermedad cardiovascular como factor principal. ${ }^{1}$ En el World Kidney Day de $2011^{3}$ señalaron que $10 \%$ de la población mundial padece insuficiencia renal crónica y $90 \%$ lo desconoce; además, estiman 1.5 millones de 
pacientes en diálisis o trasplante, con tendencia a duplicarse en 10 años. De acuerdo con estos datos, es importante la detección temprana de pacientes con insuficiencia renal crónica y su tratamiento preventivo. ${ }^{1,4}$ Esto ha impulsado a establecer criterios internacionales de diagnóstico estandarizado, confiables y oportunos, así como el desarrollo de programas de prevención inmediatos, enfocándose en la determinación y conocimiento de los factores de riesgo modificables, ${ }^{5,6}$ pues la pérdida de la función renal es progresiva, pero en su fase temprana es fácil de diagnosticar y tratar. ${ }^{7}$ En general, las buenas costumbres de ejercicio, alimentación, higiene y cuidados médicos previenen la evolución de la insuficiencia renal crónica, pero en la mayoría de la población no son llevadas a cabo satisfactoriamente y puede progresar, incluso permanecer oculta, lo que resulta en un diagnóstico difícil de establecer, impreciso, tardío, costoso y riesgoso.

El daño renal se define como las anormalidades estructurales o funcionales del riñón, determinado por marcadores que pueden identificar a los pacientes con enfermedad renal. ${ }^{1}$

\section{Definición y clasificación de la insuficiencia renal crónica}

En 2002 la Kidney Disease Outcomes Quality Initiative (KDOQI, por sus siglas en inglés) ${ }^{1}$ definió la enfermedad renal crónica como el daño renal que persiste por más de tres meses, ya sea por anormalidades funcionales o estructurales, con o sin disminución del índice de filtración glomerular ([IFG] $<60 \mathrm{~mL} / \mathrm{min} / 1.73 \mathrm{~m}^{2}$, con o sin daño renal), manifestado por trastornos $y$ concentraciones anormales de los marcadores de daño renal en sangre y orina (proteinuria) o mediante pruebas de imagen.

De acuerdo con la KDOQI (2002), , la insuficiencia renal se clasifica según el índice de filtración glomerular en $\mathrm{mL} / \mathrm{min} / 1.73 \mathrm{~m}^{2}$ de superficie corporal, en estadios 1 ( $\geq 90$, normal o aumentado) y 2 (60-89, ligera disminución), ambos con daño renal; y los estadios 3 (30-59: disminución moderada), 4 (15-29: disminución severa) y 5 (<15: insuficiencia renal terminal, insuficiencia renal establecida, pacientes que requieren diálisis o trasplante), con manifestaciones o no de daño renal. El Kidney Disease: Improving Global Outcomes (KDIGO) ${ }^{8,9}$ estableció una subclasificación del estadio 3 en 3a (45-59) y 3b (30-44). Cualquier paciente clasificado en estos estadios puede o no padecer hipertensión arterial (tensión sistólica-diastólica $\geq 140 / 90$ en adultos); por su parte, quienes padecen insuficiencia renal suelen manifestar signos y síntomas de uremia, incluso en poco tiempo pueden requerir diálisis, en caso de padecer insuficiencia crónica terminal. ${ }^{10}$

La media del índice de filtrado glomerular en adultos jóvenes (20-25 años de edad) es de 120$130 \mathrm{~mL} / \mathrm{min} / 1.73 \mathrm{~m}^{2} .^{1}$ De acuerdo con Smith, ${ }^{11}$ quien utilizó inulina, registró $127 \mathrm{~mL} / \mathrm{min} / 1.73$ $\mathrm{m}^{2}$ en hombres y $118 \mathrm{~mL} / \mathrm{min} / 1.73 \mathrm{~m}^{2}$ en mujeres, con una desviación estándar de $20 \mathrm{~mL} /$ $\mathrm{min} / 1.73 \mathrm{~m}^{2}$. En condiciones normales el índice de filtración glomerular es mayor en adultos jóvenes y disminuye en adultos de mayor edad, es decir, aproximadamente $1 \mathrm{~mL} / \mathrm{año}$ en adultos ${ }^{1}$ y después de los 20-30 años de edad ${ }^{12,13}$ varía sustancialmente, de 15 a 20\% del coeficiente de variación (desviación estándar dividida por la media) del IFG estimado (IFGe) (ajustado a 1.73 $\mathrm{m}^{2}$ de superficie corporal) o medido (IFGm). ${ }^{1,11-}$ ${ }^{13}$ Los pacientes pediátricos alcanzan los valores normales de los adultos a partir del segundo año de vida. ${ }^{1}$ El filtrado de $60-89 \mathrm{~mL} / \mathrm{min} / 1.73$ $\mathrm{m}^{2} \sin$ daño renal es normal en infantes, ancianos y adultos mayores; del mismo modo sucede en pacientes que consumen una dieta vegetariana, con disminución del volumen de líquido extracelular o daño sistémico asociado con deficiente perfusión renal. ${ }^{1}$ El valor normal del índice de filtración glomerular también se afecta por la menstruación, ${ }^{14}$ el embarazo, ta- 
maño corporal, IMC $\left(<18.5 \mathrm{~kg} / \mathrm{m}^{2} \mathrm{o} \geq 35 \mathrm{~kg} / \mathrm{m}^{2}\right.$, en quienes se prefiere implementar el IFGm) $i^{15}$ actividad física reciente $\mathrm{o}$, bien, disminución de masa muscular, incluso comorbilidades que ocasionan desnutrición y amputaciones, así como la indicación de medicamentos que interfieren con las mediciones de creatinina sérica (cefalosporinas, aminoglucósidos, cimetidina, trimetoprima, cisplatino, flucitocina)..$^{1,16-19}$

\section{Marcadores de daño renal}

Los análisis de rutina más aplicados incluyen:

\section{Estudios de imagen}

Estos exámenes pueden identificar anormalidades estructurales (forma y tamaño) y obstrucciones en el sistema renal. ${ }^{1}$ Entre los estudios más frecuentes se encuentran: ultrasonografía, ${ }^{1,20}$ radiografía y tomografía computada, con o sin medio de contraste, pues pueden dañar los tejidos renales.

En casos seleccionados se obtiene una biopsia renal para microscopia con inmunofluorescencia o microscopia electrónica. La tinción con hematoxilina-eosina, entre otras, proporciona resultados sugerentes de diversas alteraciones; sin embargo, la inmunotinción (inmunohistoquímica con peroxidasa, hibridación in situ de sondas de PCR e inmunofluorescencia) es útil para determinar los antígenos expresados por diversas infecciones virales (adenovirus, poliovirus patógenos y los de la familia de herpesvirus como: Epstein-Barr y su relación con postransplante linfoproliferativo), incluso para identificar a los pacientes con rechazo de trasplante mediado por anticuerpos (depósitos del producto de división del complemento C4d). ${ }^{21}$ La inmunotinción es capaz de diferenciar una neoplasia benigna de una maligna; por ejemplo, el adenoma metanefrítico renal, que es benigno, expresa vimentina (anticuerpo policlonal antihumano de conejo, 1:100), antígeno tumoral de Wilms (WT1, anticuerpo monoclonal antihumano de ratón, 1:200), citoqueratina (CK, anticuerpo policlonal antihumano de conejo, 1:100) y CK7 (anticuerpo monoclonal antihumano de ratón, $1: 200$ ), pero no expresa la proteína S-100 (anticuerpo policlonal antihumano de conejo, 1:100), $\alpha$-metilacil-coenzima-A racemosa (AMACR, anticuerpo monoclonal antihumano de ratón, 1:200), ni el antígeno de leucemia linfoblástica aguda (CD10, antígeno monoclonal antihumano de ratón, $1: 200) .{ }^{22}$ La amiloidosis puede ser difícil de identificar y requerir tinción de rojo Congo, microscopia electrónica, incluso espectrometría de masas de microdisección de los depósitos amiloideos, como sucede en pacientes con amiloidosis renal de apolipoproteína A-IV, en quienes se ha observado insuficiencia renal progresiva. ${ }^{23}$

\section{Examen de orina}

La concentración de albúmina en orina es un indicador temprano de daño renal, pues en algunas ocasiones se detecta en pacientes durante la evolución de la enfermedad. ${ }^{1,24}$ La proteinuria también aparece en sujetos con afección renal por hipertensión, diabetes mellitus y eventos isquémicos cardiovasculares, incluso en quienes padecen proteinuria nefrótica y no nefrótica, provocada por alguna disfunción renal (alteración de los túbulos intersticiales y vasculares) o sistémica (lupus eritematoso sistémico, sobrecarga de proteínas); en los casos de proteinuria ortostática (postural) o aislada y en quienes manifiestan proteinuria funcional (fiebre, ejercicio excesivo, frío, estrés excesivo, convulsiones, embarazo). ${ }^{24}$

En los exámenes de orina suele encontrarse:

a. Proteinuria persistente en orina de $24 \mathrm{~h}$, con concentración de $>150 \mathrm{mg} / 24$ h. ${ }^{1,24}$ Es la prueba de elección en pacientes con daño renal, principalmente en quienes padecen insuficiencia renal crónica temprana. ${ }^{1,25}$ 
b. Macroalbuminuria $(\mathrm{A} / \mathrm{Cr}=>300 \mathrm{mg} / \mathrm{g}$, detectable en tiras reactivas o dipstick $)^{20}$ y microalbuminuria $(\mathrm{A} / \mathrm{Cr}=30-300 \mathrm{mg} / \mathrm{g}$ en orina de $24 \mathrm{~h}$ ). Debe considerarse en los estudios de rutina, en la vigilancia temprana de cuidados renales de pacientes diabéticos, con alto riesgo de insuficiencia renal crónica. ${ }^{24}$

c. Índice de proteína-creatinina en una sola muestra de orina en horas indeterminadas (S-UPCl, por sus siglas en inglés). El índice anormal es $\geq 0.20 \mathrm{mg} / \mathrm{mg}^{26}$ aproximadamente, y su correlación con la prueba de proteína en orina de $24 \mathrm{~h}$ es de 0.83 para $250 \mathrm{mg} / 24 \mathrm{~h}$ ( $\mathrm{p}=<0.0001$ [el "dipstick" Clinitek Atlas PRO12 Reagent Pak es menos sensible]). ${ }^{26-28} \mathrm{El}$ índice albúmina-creatinina en una sola muestra de orina es anormal cuando es $\geq 30 \mathrm{mg} / \mathrm{g}$, ${ }^{29}$ proponiéndose como punto de corte específico $\geq 17 \mathrm{mg} / \mathrm{g}$ en hombres $y \geq 25 \mathrm{mg} / \mathrm{g}$ en mujeres. ${ }^{30,31}$ La proteinuria estimada mediante tiras reactivas, o dipstick, es $\geq 2(+)$, con $56-80 \%$ de sensibilidad y $67-92 \%$ de especificidad para proteinuria $\geq 500 \mathrm{mg} / 24$ h. ${ }^{27}$ La determinación en una sola muestra de orina para albuminuria por dipstick, combinada con el índice proteína-creatinina o albúmina-creatinina, repetida en 1-2 semanas durante 3 meses, es aceptable para establecer el diagnóstico de insuficiencia renal crónica. ${ }^{1}$ El examen general de orina con una sola muestra incluye el uso de dipstick para determinar la proteinuria, análisis de hemoglobina y sedimento para eritrocitos, leucocitos, bacterias y formación de cristales, que también se consideran marcadores de daño renal. ${ }^{1}$

\section{Análisis de suero sanguíneo}

a. Creatinina. Es un compuesto formado por la degradación del ácido orgánico nitrogenado, creatina (producida a partir de aminoácidos en el riñón, hígado y páncreas, 50\% almacenada en el músculo), que produce energía mediante la regeneración de adenosín trifosfato (ATP). La creatinina es un producto de desecho de la actividad muscular influido por la masa, la actividad muscular y el consumo de creatina (carne), además de algunos medicamentos (cimetidina y trimetoprima inhiben la secreción de creatinina). ${ }^{1}$ Este producto es detectable en la sangre y normalmente eliminado por la orina, mediante su filtrado libre en el glomérulo y secreción en el túbulo proximal. La determinación de creatinina sérica es el estudio de elección para evaluar la correcta función de los riñones, ${ }^{32}$ cuyo aumento de su concentración indica deficiencias en la filtración. Se utiliza para estimar el daño renal agudo en conjunto con la determinación de nitrógeno ureico (por sus siglas en inglés: BUN), aunque con baja sensibilidad y especificidad. ${ }^{33}$ No debe indicarse sólo para evaluar la función renal, pues la concentración normal de creatinina sérica tiene un amplio margen de variabilidad, ${ }^{10}$ incluso puede mantenerse en concentraciones normales cuando se encuentra alterada la función renal. ${ }^{34-36}$ Debido a esto, preferentemente se utilizan valores de referencia como marcadores de filtración endógenos, en el que se aplican ecuaciones para el estimado del índice de filtrado glomerular (IFGe) en la clasificación y evolución de la insuficiencia renal crónica. ${ }^{1}$ La creatinina sérica también muestra variaciones por factores asociados con los métodos de laboratorios utilizados, incluso si éstos utilizan el mismo método, pues afectan en gran medida el índice de filtrado glomerular, sobre todo en sus estimaciones altas. ${ }^{37,38}$ Por tanto, se ha procurado unificar criterios mundialmente $^{4}$ y en la actualidad es obligatorio para los laboratorios y compañías fabricantes de métodos automatizados (según 
la Directive 98/97 EC of the European Parliament and Council de 1998), ${ }^{39}$ incluso ya es un hecho en algunos países (EUA), estandarizar los valores de creatinina al método internacionalmente aceptado de referencia, mediante espectrometría de masa por dilución isotópica (IDMS del inglés "isotope dilution mass spectrometry") o con técnicas semejantes como: cromatografía de gases (GC-IDMS), que representa un método simple y aceptable, o cromatografía líquida (LC-IDMS), que es mucho más fácil y posiblemente viable en un futuro. ${ }^{4}$ IDMS es de difícil acceso, pero los materiales de referencia estándar (SRM, por sus siglas en inglés) para determinar la creatinina en métodos rutinarios pueden ser trazables ("traceable") a valores de la IDMS. ${ }^{40,10}$ Debe incluirse en las muestras serológicas el material de referencia secundario (por ejemplo: CAP LN-24, ST SRM 967) como muestras control de verificación de que el método aplicado es trazable a IDMS, ya que se elaboran con un material de referencia primario (NIST SRM 914a, NIST SRM 914), que representa el control verdadero en los métodos GC-IDMS o LC-IDMS para establecer las unidades internacionales estándar de creatinina en la calibración de los IDMS. ${ }^{41}$ El material de referencia lo fabrica o prepara el College of American Pathologist (CAP) y el National Institute of Standards and Technology (NIST) para establecer el método de obtención de creatinina, de acuerdo con el Clinical and Laboratory Standards Institute (CLSI, 1999). ${ }^{4,40,42-44}$ El material primario y los métodos de referencia para determinar la creatinina son aprobados por el Joint Committee for Traceability in Laboratory Medicine (JCTLM). ${ }^{4}$ Existen compañías con aparatos y métodos adaptados para estandarizar automáticamente el valor de creatinina, similar al que se obtiene por IDMS, como el enzimático de Roche. ${ }^{14,41,45}$
Cualquier método enzimático, ya sea Jaffe con base a la alcalinización de ácido pícrico, pruebas de punto de cuidado (POC: point of care testings) o cromatografía líquida de alta definición (HPLC), que no se encuentre estandarizado al IDMS, no podrá establecer los valores de creatinina estandarizado a IDMS y el valor no será aplicable a las ecuaciones para evaluar el índice de filtrado glomerular de más reciente aceptación. 14,16,17,41,46

b. Cistatina $\mathrm{C}(\mathrm{CysC})$. Es una proteína de bajo peso molecular, no glucosilada, producida constantemente por todas células nucleadas; además, es filtrada libremente por el glomérulo y catabolizada en el túbulo proximal. ${ }^{47}$ Comparada con la creatinina, no está influida por la masa y actividad muscular en pacientes pediátricos, adultos mayores y sujetos obesos; ${ }^{16}$ sin embargo, existen factores extrarrenales que afectan su función, como el hipotiroidismo, el tratamiento con corticoesteroides, etc. Esta molécula se considera, más bien, un indicador de inflamación. ${ }^{33,48-52} \mathrm{Su}$ producción tiene variaciones conforme avanza la edad ${ }^{52} y$ hasta la fecha no existe un valor estandarizado, ni heterogeneidad en los métodos de laboratorio para determinarla. ${ }^{53}$ La ecuación más reciente del índice de filtración glomerular, que incluye la creatinina estandarizada y la cistatina $\mathrm{C}$ de una metodología específica, aunque aún no completamente aceptada, ha dado buenos resultados. ${ }^{16,17,46}$ Otra determinación menos efectiva que la cistatina $C$ para evaluar el daño renal es la proteína $\beta$-traza. ${ }^{47,55}$

Análisis de rutina adicionales sugerentes de daño renal

- Concentración elevada de nitrógeno ureico en sangre (BUN de $100 \mathrm{mg} / \mathrm{dL}$ ). 
Aunque puede expresarse en enfermedades no renales, también indica daño renal severo. $^{33,47}$

- Concentración alta de ácido úrico por producción elevada de uratos, excreción renal disminuida, o ambas. ${ }^{56}$ Esta alteración se ha relacionado con hipertensión, obesidad, hipertrigliceridemia, ${ }^{57}$ enfermedad cardiovascular, enfermedad renal e insuficiencia renal crónica. ${ }^{57,58} \mathrm{Su}$ propiedad antioxidante puede volverse prooxidante en la placa aterosclerótica ${ }^{56}$ y originar disfunción endotelial, ${ }^{59}$ lo que incrementa la tensión arterial, ${ }^{57}$ disminuye el filtrado glomerular ${ }^{60}$ y aumenta la presión glomerular. ${ }^{61}$

- El perfil electrolítico incluye la determinación de sodio, potasio, cloruro y bicarbonato. La concentración elevada de potasio indica disminución de su secreción en el túbulo distal y la hipercalemia es una complicación de la insuficiencia renal que requiere tratamiento de por vida. ${ }^{47,62}$

\section{Biomarcadores de daño renal utilizados en investigación}

Los biomarcadores aplicados para establecer el diagnóstico de insuficiencia renal crónica son efectivos para estimar las concentraciones bajas de homoarginina sérica ${ }^{63}$ y altas de homocisteína plasmática, ${ }^{56}$ además de identificar la expresión excesiva del factor de crecimiento de fibroblastos 23 (FGF-23) (4-66 $^{6}$ disminuida del gen klotho (RNAm o proteína). ${ }^{66,67}$

Los biomarcadores implementados para daño renalagudo, que incluso pueden aplicarse más temprano que la determinación de creatinina son:

a. Interleucina 18 (IL-18). Esta citocina puede detectarse por inmunohistoquímica en células epiteliales tubulares (mediante su expresión de ARN mensajero) o mediante la concentración en orina. Su detección es evidente después de $12 h,{ }^{33,68}$ pero no es específica para establecer el diagnóstico de insuficiencia renal crónica. Es una citocina proinflamatoria, biomediadora y biomarcadora de insuficiencia renal aguda isquémica, específica para detectar el grado de daño renal agudo, diferenciándolo del rechazo de aloinjerto renal, síndrome nefrótico de cambio mínimo (comparado con nefropatía por inmunoglobulina A), proteinuria y actividad de la enfermedad. La inhibición de IL-18 (anticuerpos neutralizantes, ${ }^{69}$ proteína de unión de IL-18 exógena [IL-18 BP] ${ }^{70} \mathrm{o}$ inhibición de la caspasa $1^{71}$ ) confiere protección contra el daño renal agudo en ratones. ${ }^{33}$

b. Lipocalina relacionada con el neutrófilo gelatinasa (NGAL). Es un polipéptido pequeño, resistente a proteasas, componente crítico de inmunidad innata por infección bacteriana, expresado por las células inmunitarias, hepatocitos y células tubulares del riñón en varios tipos de la enfermedad. ${ }^{33,72}$ La concentración urinaria o sérica elevada de NGAL, determinada por ELISA o Western blot, ${ }^{73,74}$ incluso por RT-PCR en los túbulos renales, representa un biomarcador temprano con alta sensibilidad y especificidad, no invasivo y predictivo de daño renal isquémico en niños y adultos, entre 2 y $18 \mathrm{~h}$ (creatinina 2 a 3 días) después de haber efectuado la cirugía cardíaca y de arresto cardíaco, respectivamente; además, se correlaciona fuertemente con cambios en la concentración de creatinina, periodo de daño renal, estancia hospitalaria y mortalidad. Puede detectarse en pacientes con daño renal nefrotóxico e isquémico, y aunque no se menciona en estudios relacionados con insuficiencia renal crónica, se han 
detectado elevadas concentraciones en orina de pacientes con enfermedad renal poliquística autosómica dominante. También se ha observado la relación entre la función residual renal y las concentraciones de NGAL en suero y orina; ${ }^{75}$ también se ha detectado elevada en pacientes en diálisis. ${ }^{76}$ La concentración elevada de NGAL urinaria, BUN y creatinina se ha relacionado con lesión del epitelio tubular renal, incluso se ha estudiado NGAL urinaria como biomarcador de actividad en pacientes con nefritis por lupus eritematoso sistémico. ${ }^{33,77}$

C. Molécula de daño renal 1 (KIM-1) en expresión del ARNm. Puede determinarse en proteínas y en la orina, ${ }^{78}$ y la hibridación in situ e inmunohistoquímica muestran que está expresada en células epiteliales en regeneración de los túbulos proximales. ${ }^{79}$ Representa el biomarcador con mejores resultados como predictor de diálisis y mortalidad (el segundo mejor es la NGAL). ${ }^{33}$

\section{Índice de filtración glomerular (IFG)}

Hasta ahora se considera el mejor indicador de la función renal. ${ }^{11,40}$ Puede realizarse de tres formas:

1. Cálculo de la depuración de marcadores endógenos. Se realiza mediante la recolección de orina de 24 horas y la aplicación de alguna de las siguientes ecuaciones: depuración de creatinina (es la más utilizada, Cuadro 1), depuración de creatinina con bloqueo tubular con cimetidina, depuración de insulina y depuración de urea-depuración de creatinina. ${ }^{80}$ En pacientes con índice de masa corporal normal, la estimación del IFG con creatinina es más precisa con la ecuación $\operatorname{MDRD}_{6}(1999)^{81}$ que con la depuración de orina de 24 h. ${ }^{1,4,82}$ Las pruebas de orina de $24 \mathrm{~h}$ tienen como desventaja un proceso largo de colecta, lo que dificulta obtener la cantidad completa de orina ${ }^{10,82}$ y no es práctica en estudios epidemiológicos para detectar los casos de insuficiencia renal crónica; sin embargo, representan las pruebas de rutina.

2. Cálculo de la depuración con algún marcador externo. Es una sustancia que al aplicarla en el organismo mantiene una concentración estable en el plasma, por ser fisiológicamente inerte y de la que se espera una cantidad similar excretada en orina, con la que puede medirse el índice de filtración glomerular (IFGm) mediante la diferencia de la cantidad introducida intravenosamente versus la cantidad eliminada en orina ${ }^{14,19,83,84}$ (por ejemplo, con inulina, que representa la prueba de referencia) ${ }^{1} \mathrm{o}$, bien, versus la cantidad que permanece en plasma (por ejemplo, con iohexol en una sola toma, a 4, 7 o 24 h). ${ }^{85}$ Se prefiere administrar iohexol, debido a su baja toxicidad y por no provocar efectos adversos en niños y adolescentes, incluso para establecer el diagnóstico de insuficiencia renal. ${ }^{86}$ Posteriormente se aplica una ecuación para calcular la depuración (Cuadro 1), cuyo valor se ajusta al estándar de superficie corporal (ASC) de $1.73 \mathrm{~m}^{2}$, en conjunto con la ecuación para ASC de DuBois D y DuBois EF (1916) ${ }^{1,87}$ para adultos, y la ecuación para ASC de Haycock su grupo $(1978)^{88}$ para niños y adolescentes. ${ }^{86}$ Otros marcadores externos son los radioisótopos ${ }^{125}$ I-iothalamato ${ }^{14,84}$ de EDTA $\left({ }^{51} \mathrm{Cr}\right.$-EDTA) y DTPA $\left({ }^{99 \mathrm{~m} T c-D T P A}\right)$ en niños y adultos. ${ }^{86,89-94}$ Se considera la prueba de referencia para evaluar la función renal, pero es un proceso difícil de realizar, costoso y prolongado, además de provocar lesiones en los tejidos renales. ${ }^{19}$ Esta 
Cuadro 1. Ecuaciones más utilizadas actualmente para el cálculo de la depuración de creatinina, índice de filtración glomerular medido o estimado y depuración de creatinina en orina de 24 horas

Dep Creat $(\mathrm{mL} / \mathrm{min} / 1.73 \mathrm{~m} 2)=\mathrm{CrU} / \mathrm{CrS} \times \mathrm{VM} \times 1.73 / \mathrm{SC}$; donde:

$\mathrm{CrU}=$ creatinina urinaria $\mathrm{mg} / \mathrm{d} ; \mathrm{CrS}=$ creatinina sérica $\mathrm{mg} / \mathrm{dL} ; \mathrm{VM}=$ volumen $24 \mathrm{~h} / 1440 ; \mathrm{SC}=$ superficie corporal del paciente calculado según la tabla de Du Bois con el peso y la talla.

Para IFGm con el marcador externo inulina (prueba de oro, aunque en niños se prefiere iohexol):

$$
\text { GFR }=\underline{U}_{\underline{\text { in }}} \frac{\times V}{P_{\text {in }}}
$$

$\mathrm{V}=$ volumen de orina en $\mathrm{mL} / \mathrm{min}, \mathrm{U}_{\text {in }}=$ concentración de inulina en orina, $\mathrm{P}_{\text {in }}=$ concentración de inulina en plasma; el resultado será la depuración de inulina en $\mathrm{mL} / \mathrm{min}$, cuyo valor se ajusta al estándar de superficie corporal de $1.73 \mathrm{~m}^{2}$ (tomado de KDOQI, 2002).

Para cálculo de área de superficie corporal (ASC o siglas en inglés BSA) en adultos, ecuación de Du Bois D y Du Bois EF, 1916: ASC $\left(\mathrm{m}^{2}\right)=0.007184 \times(\text { peso en } \mathrm{kg})^{0.425} \times(\text { altura en } \mathrm{cm})^{0.725}$

Para cálculo de área de superficie corporal (ASC o siglas en inglés BSA) en niños, ecuación de Haycock GB et al., 1978 ${ }^{71,75}$ : BSA $\left(\mathrm{m}^{2}\right)=0.024265 \times(\text { peso en } \mathrm{kg})^{0.5378} \times(\text { altura en } \mathrm{cm})^{0.3964}$

Para IFGe con creatinina sérica estandarizada a IDMS, en adultos, CKD-EPI-GFR equation Levey AS, et al., 2009 expresado como una sola ecuación:

$\mathrm{GFR}=141 \times \mathrm{min}(\mathrm{CrS} / \mathrm{k}, 1)^{\alpha} \times \max (\mathrm{CrS} / \mathrm{k}, 1)^{-1.209} \times 0.993^{\mathrm{Edad}} \times 1.018$ [para mujer] $\times 1.159$ [para raza negra]

Donde: $\mathrm{CrS}=$ creatinina sérica estandarizada en $\mathrm{mg} / \mathrm{dL}, \mathrm{k}=0.7$ para mujer y 0.9 para hombre, $\alpha=-0.329$ para mujer $y$ -0.411 para hombre, min indica el mínimo de CrS/k ó 1 y max indica el máximo de CrS/k o 1.

Para IFGe con creatinina sérica no estandarizada a IDMS, en adultos, MDRD Levey AS et al., 2000:

IFG $\left(\mathrm{mL} / \mathrm{min} / 1.73 \mathrm{~m}^{2}\right)=186 \times(\mathrm{CrS} \mathrm{mg} / \mathrm{dL})^{-1.154} \times(\mathrm{edad})^{-0.203} \times(0.742$ para mujer $) \times(1.210$ para afroamericano $)$;

o la de Cockcroft DW y Gault MH, 1976:

$\mathrm{C}_{\mathrm{Cr}}(\mathrm{mL} / \mathrm{min})=(140$ - edad en años $) \times$ peso en $\mathrm{kg} \times(0.85$ para mujer $)$; dónde:

$72 \times \mathrm{Cr}_{\mathrm{s}}$

$\mathrm{C}_{\mathrm{Cr}}=$ depuración de creatinina, $\mathrm{Cr}_{\mathrm{s}}=$ creatinina sérica en $\mathrm{mg} / \mathrm{dL}$; requiere realizar un ajuste por área de superficie corporal utilizando la ecuación de DuBois D, DuBois EF 1916, ${ }^{1,74}$ para trasladarlo a $\mathrm{mL} / \mathrm{min} / 1.73 \mathrm{~m}^{2}$;

o la modificada por Rostoker G et al., 2007 y 2009:

Cockcroft-Gault modificada con ASC $=\underline{1.73 \mathrm{~m}^{2}} \underline{\underline{2} \text { CCr Cockcroft-Gault }}$

Donde: ASC del paciente

$\mathrm{CCr}=$ depuración de creatinina con la ecuación de Cockcroft-Gault en $\mathrm{mL} / \mathrm{min}$, ASC = área de superficie corporal con la ecuación de DuBois D, DuBois EF 1916 en m².

Para elFG en niños, Schwartz GJ et al., 2012 para creatinina estandarizada a IDMS (CrS) y cistatina C (CysC) obtenida por método nefelométrico de Siemens Health Care:

$\mathrm{eGFR}=39.8^{*}[\mathrm{ht}(\mathrm{m}) / \mathrm{CrS}]^{0.456}[1.8 / \mathrm{Cys}]^{0.418}[30 / \mathrm{BUN}]^{0.079} 1.076^{\mathrm{male}}[\mathrm{ht}(\mathrm{m}) / 1.4]^{0.179}$

y para uso clínico, cuando las variables ht (altura), $\mathrm{CrS}$ o CysC se pueden ver afectadas (obesidad, corticosteroides, masa muscular disminuida), la ecuación bedside:

eGFR = 0.413(ht/(cm)/CrS), o $41.3(\mathrm{ht} / \mathrm{CrS})$;

o las de Grubb A, 2010 71,81

para $\mathrm{ht} / \mathrm{CrS}: \mathrm{eGFR}=42.3(\mathrm{ht} / \mathrm{CrS})^{0.78} \mathrm{y}$

para CysC: eGFR $=70.69(\text { CysC })^{-0.931}$

esta última incluso con el método inmunoturbidimétrico para cistatina $\mathrm{C}^{71}$.

Para elFG en niños, con solo creatinina sérica no estandarizada a IDMS, ecuación de Schwartz GJ, et al., 1976:

$\mathrm{C}_{\mathrm{Cr}}\left(\mathrm{mL} / \mathrm{min} / 1.73 \mathrm{~m}^{2}\right)=\underline{(\mathrm{k}) \text { (altura) }}$

$\mathrm{Cr}_{\mathrm{s}}$

k= coeficiente que varía siendo de 0.55 para niños mayores de 1 año y niñas adolescentes; 0.7 en niños adolescentes; 0.33 para niños de bajo peso al nacer de recién nacido a 1 año; 0.45 para recién nacidos a término y hasta 1 año. $\mathrm{C}_{\mathrm{Cr}}=$ creatinine clearence; $\mathrm{Cr}_{\mathrm{s}}=$ creatinina sérica en $\mathrm{mg} / \mathrm{dL}$ y la altura en $\mathrm{cm}$.

O ecuación de Counahan-Barratt, Counahan y su grupo (1976):

$\operatorname{eGFR}\left(\mathrm{mL} / \mathrm{min} / 1.73 \mathrm{~m}^{2}\right)=\underline{0.43 \times \text { altura }}$

altura en $\mathrm{cm}, \mathrm{Cr}_{\mathrm{s}} \mathrm{mg} / \mathrm{dL}$

$$
\mathrm{Cr}_{\mathrm{s}}
$$

Dep Creat: depuración de creatinina. IFG: índice de filtración glomerular. IFGm: índice de filtración glomerular medido. IFGe: índice de filtración glomerular estimado. Fuente: referencia 81. 
prueba se utiliza para investigación y no se aplica comúnmente como apoyo en el diagnóstico clínico.

3. Ecuaciones para la estimación del índice de filtración glomerular (IFGe). Se utilizan comúnmente para la clasificación, evolución y tratamiento de la insuficiencia renal crónica y, últimamente, para establecer su diagnóstico. ${ }^{18}$ Son pruebas económicas y con alto grado de confiabilidad, ${ }^{1}$ que las hace epidemiológicamente más aplicables. Considera valores en suero del marcador interno de creatinina y algunos de cistatina $C$.

- Ecuaciones para evaluar el índice de filtrado glomerular (IFGe) con creatinina sérica estandarizada al método de espectrometría en masa de dilución de isótopo (IDMS)

(Cuadro 1). En la actualidad, la ecuación más aceptada para adultos, por proporcionar valores confiables de IFGe, es la del Chronic Kidney Disease Epidemiology Collaboration (CKD-EPI 2009) $)^{1,14} y$ al igual que la Modification of Diet in Renal Disease (MDRD) Study Equation (MDRD ${ }_{4}$ ) de cuatro elementos reexpresada, ${ }^{41}$ se realizaron con valores estandarizados trazables de creatinina al IDMS y comparando la depuración de un marcador externo como prueba de referencia. ${ }^{95} \mathrm{La}$ $\mathrm{MDRD}_{4}$ de $2007^{41}$ es la reexpresión de la $\mathrm{MDRD}_{4}$ del año $2000^{96}$ para creatinina sérica no estandarizada. Los valores de creatinina no estandarizados al IDMS no son aplicables a la CKD-EPI (2009) ${ }^{14}$ ni a la MDRD $_{4}$ (2007). ${ }^{16,17,41}$ Shafi y su grupo ${ }^{95}$ compararon ambas ecuaciones y observaron que la CKD-EPI (2009) ${ }^{14}$ reclasificó $19.4 \%$ de los individuos con filtración glomerular de 30-59 a 60-89 $\mathrm{mL} / \mathrm{min} / 1.73 \mathrm{~m}^{2}$, con disminución del riesgo de mortalidad por toda causa $y$ por enfermedad cardiovascular, mientras que $0.5 \%$ de $>60 \mathrm{~mL} / \mathrm{min} / 1.73 \mathrm{~m}^{2}$, a un filtrado menor y con mayor riesgo de mortalidad por toda causa y por enfermedad cardiovascular. El estudio de Matsushita y sus colaboradores ${ }^{97}$ reportó $34.7 \%$ de los pacientes con filtración glomerular de $45-59 \mathrm{~mL} / \mathrm{min} / 1.73 \mathrm{~m}^{2}$, reclasificados a 60 $89 \mathrm{~mL} / \mathrm{min} / 1.73 \mathrm{~m}^{2}$, con disminución del riesgo de mortalidad por toda causa, por enfermedad cardiovascular e insuficiencia renal crónica terminal; además, mostraron que la prevalencia en los estadios 3 a 5 disminuyó de 8.7 a $6.3 \%$.

- CKD-EPI (2009) $)^{14}$ para creatinina estandarizada. Esta ecuación, actualmente recomendada por la National Kidney Foundation, ${ }^{16,17}$ ajusta la estimación del índice de filtración glomerular por sexo, edad, altura, peso y raza para expresar un resultado en $\mathrm{mL} / \mathrm{min} / 1.73 \mathrm{~m}^{2}$ de área de superficie corporal. Fue desarrollada para las razas blanca y negra de Estados Unidos; sin embargo, un estudio la aplicó en la población latina $(n=497)$, incluida la México-Norteamericana $(69 \%) .^{45} \mathrm{Su}$ efectividad varía según el país en que se utiliza. Arreola-Guerra y sus cooautores, ${ }^{98}$ quienes la aplicaron en una población sana de México, reportaron una correlación de Pearson $\left(r^{2}\right)$ de 0.65 y precisión $\left(\mathrm{P}_{30}\right)$ de $83.5 \%$ versus la medición del índice de filtración glomerular (IFGm). Entre sus resultados encontraron aceptable la ecuación, pues la relación mejora según el IMC $>26 \mathrm{~kg} / \mathrm{m}^{2}$, debido a que la media poblacional de área de superficie corporal en mexicanos es poco menor a $1.73 \mathrm{~m}^{2}$; por tanto, se recomienda utilizar un ajuste individual a los valores de creatinina, en conjunto con la ecuación de DuBois D y DuBois EF, (1916). ${ }^{87,99}$ La ecuación CKD-EPI de 2012 ${ }^{17,46}$ para creatinina estandarizada y cistatina $C$ trazable al International Federation of 
Clinical Chemistry Working Group for Standardization of Serum Cystatin C y al Institute for Reference Materials and Measurements Certified Reference Materials ofrece mejores resultados que los valores individuales; sin embargo, no se encuentra oficialmente recomendada por las agrupaciones de nefrólogos. Schwartz y su grupo ${ }^{86}$ recomiendan, para niños y adolescentes, que cuando no se administre iohexol para determinar el índice de filtración glomerular, se utilice su ecuación multivariada de creatinina sérica mediante método enzimático o HPLC en ambas trazables a IDMS, y para cistatina $\mathrm{C}$ con método nefelométrico de Siemens Health Care, mientras se estandariza mundialmente para CysC. Para uso clínico mencionan como alternativa sus ecuaciones de estimación del índice de filtración glomerular (IFGe) univariadas, cuando las variables altura (ht), creatinina sérica o cistatina $C$ puedan afectarse por obesidad, corticosteroides o masa muscular disminuidas o, bien, la ecuación bedside o las de Grubb (2010) $)^{86,100}$ para creatinina sérica, cistatina $\mathrm{C}$ o cistatina $\mathrm{C}$ mediante método inmunoturbidimétrico. ${ }^{86}$

Ecuaciones para la estimación del índice de filtración glomerular (IFGe), recomendadas cuando no hay forma de estandarizar el valor de creatinina al método de IDMS (Cuadro 1): $:^{1,41}$

- Ecuación de MDRD $_{4}(2000)^{96}$ para valores de creatinina sérica no estandarizada. Levey y sus coautores ${ }^{41}$ consideran inciertos los valores de la estimación del índice de filtración glomerular (IFGe) mayores de 60 y como adecuados los menores de 60 . El NKDEP ${ }^{18}$ sugiere reportar valores de IFGe precisos y en $\mathrm{mL} / \mathrm{min} / 1.73 \mathrm{~m}^{2}$, en estos valores iguales o menores de 60 y para los valores mayores a 60 como "valores mayores a 60". Es la simplificación del $\mathrm{MDRD}_{6}$
(1999), ${ }^{81}$ determinada con creatinina mediante la metodología de Jaffe, comparada con la depuración de algún marcador externo como prueba de referencia. ${ }^{41}$

- Ecuación de Cockcroft-Gault (1976). ${ }^{1,27,101-}$ ${ }^{103}$ Se calculó con base en un coeficiente de valor medio de orina de 24 horas de varios pacientes de diversas edades, con creatinina como marcador endógeno, para predecir la depuración de creatinina sin colección de orina de $24 \mathrm{~h}$. El resultado $(\mathrm{mL} / \mathrm{min})$ debe ajustarse al área de superficie corporal (ASC), con la ecuación de DuBois D y DuBois EF (1916), ${ }^{1,87}$ para la expresión estándar en $\mathrm{mL} / \mathrm{min} / 1.73 \mathrm{~m}^{2}$. La modificación de Rostoker y su grupo (2007 y 2009) ${ }^{104,105}$ evalúa nefropatías no diabéticas y la evolución de la insuficiencia renal crónica con buenos resultados.

- Ecuación de Schwartz (1976). ${ }^{105}$ Se recomienda en niños. ${ }^{1}$ Fue determinada con valores de creatinina mediante el método de Jaffe.

- Ecuación de Counahan-Barratt (1976). ${ }^{107}$ Se determinó con valores de creatinina, por metodología Jaffe, con previa remoción de cromógenos sin creatinina que no fueran $\mathrm{Cr}$, por adsorción en una resina de intercambio iónico. Esta ecuación se aplica en niños de la comunidad europea y por la KDOQI (2002). ${ }^{1}$

Para valores de creatinina sérica no estandarizada, la $\mathrm{MDRD}_{4}(2000)^{96}$ no difiere significativamente de los resultados obtenidos con la MDRD (1999), $, 1,96$ incluso se discute que es mejor la determinación con la $\mathrm{MDRD}_{6}(1999)^{81}$ que con la Cockcroft-Gault (1976) ${ }^{81,101}$ o MDRD $_{4}(2000)^{96}$ para establecer el diagnóstico de insuficiencia renal crónica terminal. También se ha sugerido una mejor determinación con la Cockcroft-Gault $(1976)^{101}$ corregida (ajustada) que con la MDRD 4 (2000). ${ }^{96,103-105}$ 
Detección de casos y evolución del daño renal en pacientes con insuficiencia renal temprana y terminal

La enfermedad renal suele iniciar durante la etapa adulta y evoluciona lentamente. ${ }^{10} \mathrm{La}$ Kidney Disease Outcomes Quality Initiative de 2002 (KDOQI) ${ }^{1}$ sugiere diversos factores de riesgo asociados con la insuficiencia renal crónica (principalmente diabetes e hipertensión) y los clasifica según la susceptibilidad, inicio y evolución a insuficiencia crónica. Entre los factores de evolución de la enfermedad pueden estar implicados los factores de inicio, pues se desconoce el momento en que inicia la insuficiencia renal crónica.

El estudio de Amato y su grupo, ${ }^{108}$ efectuado en la población mexicana, aplicando la ecuación de Cockcroft-Gault101 reportaron que en personas con depuración de creatinina (CCr) menor de 60 $\mathrm{mL} / \mathrm{min} / 1.73 \mathrm{~m}^{2}$ de área de superficie corporal $34 \%$ fueron casos con hipertensión y $25 \%$ con diabetes; por su parte, quienes resultaron con CCr menor de $15 \mathrm{~mL} / \mathrm{min} / 1.73 \mathrm{~m}^{2}$, se observaron $58 \%$ de los casos con hipertensión y $40 \%$ con diabetes. El ensayo de Méndez-Durán y sus colaboradores, ${ }^{109}$ realizado en derechohabientes del IMSS con insuficiencia renal crónica terminal, reportó $48.5 \%$ de pacientes con diabetes, $19 \%$ con hipertensión, $12.7 \%$ con glomerulopatías crónicas y $19.8 \%$ con otras (9.2\% correspondió a enfermedades no establecidas).

Los pacientes con insuficiencia renal crónica en etapa inicial no suelen expresar valores bajos del índice de filtrado glomerular; sin embargo, conforme avanza el tiempo, éste va disminuyendo. ${ }^{1}$ La evolución a insuficiencia renal crónica terminal puede detenerse o alargarse cuando el daño renal se detecta en estadios tempranos, ${ }^{27}$ que puede pasar inadvertido por ser asintomático hasta que resta $10 \%$ de la función renal en pacientes con insuficiencia renal terminal y se manifiesta con signos de uremia. ${ }^{1}$
El daño renal es asintomático en pacientes con insuficiencia crónica temprana, pero sugiere proteinuria, hematuria o disminución del índice de filtrado glomerular. ${ }^{27}$ La hematuria y piuria pueden indicar daño renal que no afecta al glomérulo y solose encuentre en los túbulos o el intersticio, por lo que en estos casos se observa disminución del IFG. ${ }^{1}$ En algunos estudios epidemiológicos, un marcador importante para la identificación de pacientes adultos con insuficiencia renal crónica es el resultado de IFGe $\leq 60 \mathrm{~mL} / \mathrm{min} / 1.73 \mathrm{~m}^{2},{ }^{27}$ lo que implica una pérdida $\geq 50 \%$ de la función renal y debajo de esta concentración se incrementan las complicaciones para padecer insuficiencia renal crónica. ${ }^{1,10,95,97}$

El estudio de Chadban y su grupo, ${ }^{26}$ efectuado en la población australiana igual o mayor de 25 años de edad, reportó a $11.2 \%$ con disminución del IFGe a $<60 \mathrm{~mL} / \mathrm{min} / 1.73 \mathrm{~m}^{2}(95 \% \mathrm{Cl}$ : $8.6 \%, 13.8 \%)$; a $4.6 \%$ con hematuria $(95 \% \mathrm{Cl}$ : $3.8,5.4 \%)$ y $2.4 \%$ con proteinuria $(95 \%$ IC: $1.6 \%, 3.1 \%$ ) con el S-UPCI. Al menos uno de estos marcadores apareció en $16 \%$ de la población. La edad, el sexo y la hipertensión arterial se asociaron con disminución del IFGe y con hematuria; por su parte, la edad, diabetes meIlitus e hipertensión arterial se relacionaron con proteinuria. Estos datos sugieren que es efectiva la identificación en ese sector de la población con algunos de estos marcadores y será efectivo también para el seguimiento, tratamiento y disminución de casos de la insuficiencia renal terminal.

Recomendaciones actuales para establecer el diagnóstico de insuficiencia renal crónica temprana

La detección e identificación del mayor número posible de casos de insuficiencia renal crónica temprana u oculta, además de la disminución de pacientes con insuficiencia renal terminal 
implica que toda persona con esta enfermedad o con alto riesgo de la misma debe practicarse exámenes de proteinuria e IFG. ${ }^{10}$ Es importante estandarizar cualquier valor de creatinina y efectuarse en conjunto con la estimación del índice de filtrado glomerular. ${ }^{1,4,10}$ Actualmente, el National Kidney Disease Educational Program (NKDEP) ${ }^{18}$ señala para todo laboratorio de EUA estimar de manera rutinaria los valores de creatinina sérica $(\mathrm{CrS})$ estandarizada al IDMS (o "traceable" a IDMS) junto con el valor de IFGe, preferentemente con la ecuación CKD-EPI $(2009)^{14}$ para CrS y, además del anterior uso de las ecuaciones para IFGe para la clasificación de la insuficiencia renal crónica y el ajuste de medicaciones en los hospitales, también se realice para establecer el diagnóstico de la enfermedad, siempre considerando las posibles condiciones que generan imprecisiones en los valores de creatinina sérica y en resultados de las ecuaciones de estimación del índice de filtrado golerular. ${ }^{1,16-19}$

\section{Situación en México}

En países industrializados la detección y tratamiento oportuno de insuficiencia renal crónica son accesibles para toda la población, incluso existen registros de pacientes que requieren reemplazo renal, para facilitar el conocimiento de la incidencia y prevalencia de la insuficiencia renal crónica terminal, aspectos que en México son muy limitados. ${ }^{108}$ Según los datos del INE$\mathrm{Gl}^{1}{ }^{110}$ en 2010 se registraron $66.3 \%$ de mujeres y $62.7 \%$ de hombres con acceso a los servicios de salud, lo que indica al menos $33 \%$ de la población no tiene acceso a los servicios de salud ni a sus registros. Amato y su grupo, ${ }^{108}$ quienes utilizaron la ecuación de Cockcroft-Gault (1976) ${ }^{101}$ en pacientes de atención primaria del estado de Michoacán, mayores de 18 años de edad, determinaron que la prevalencia de casos con depuración de creatinina $(\mathrm{CCr})$ menor de 60 $\mathrm{mL} / \mathrm{min} / 1.73 \mathrm{~m}^{2} \mathrm{ASC}$, fue de 80,788 por cada millón de habitantes (pmh); y con depuración de creatinina menor de $15 \mathrm{~mL} / \mathrm{min} / 1.73 \mathrm{~m}^{2}$ de 1,142 pmh; Además, sugieren que en México 1 de 4 personas tiene acceso a tratamiento renal. El estudio de García-García y sus colaboradores, ${ }^{111}$ efectuado en Jalisco, reportó el limitado acceso a los servicios de salud para terapia de reemplazo renal en pacientes con bajos recursos económicos sin seguro social, lo que proporciona una visión de la situación. Por su parte, el Registro Estatal de Diálisis y Trasplante de Jalisco (REDTJAL) muestra un incremento en la incidencia de pacientes, con 92 casos por cada millón de habitantes (ppmh) en 1999 a 372 ppmh en 2007, esta última cifra se considera la más alta del mundo. ${ }^{112,113}$ Medina-Escobedo y su grupo ${ }^{114}$ encontraron $4.8 \%$ de pacientes con filtrado de $30-59 \mathrm{~mL} / \mathrm{min} / 1.73 \mathrm{~m}^{2}$ mediante la escala $\mathrm{MDRD}_{4}(2000),{ }^{96}$ en un estudio piloto en Yucatán, con sujetos de bajos recursos económicos, mayores de 18 años de edad, sin diabetes ni edema. Entre sus resultados encontraron $84.8 \%$ con sobrepeso y obesidad, en $82 \%$ de la mujeres, mientras que Amato y su equipo de trabajo ${ }^{108}$ reportaron un filtrado de $30-59 \mathrm{~mL} / \mathrm{min} / 1.73 \mathrm{~m}^{2}$ en $8.1 \%$ de sus casos y en $4.2 \%$ de los pacientes establecido por el grupo del KDOQI (2002), ${ }^{1}$ tomando datos de NHANES. El ensayo de Soto-Domínguez y su grupo, ${ }^{115}$ realizado en pacientes de atención primaria en Tamaulipas, mayores de 50 años de edad, encontró $31 \%$ de los casos en estadio 3 y $58 \%$ en estadio 2 de insuficiencia renal crónica, mediante la ecuación de Cockcroft-Gault ${ }^{101}$ ajustada por área de superficie corporal.

\section{CONCLUSIONES}

La disminución de pacientes en diálisis implica que todos los laboratorios determinan los valores de creatinina sérica estandarizada y los reporten en conjunto con los resultados del índice de filtrado glomerular con la ecuación CKD-EPI (2009)..$^{14-18}$ En caso de no encontrarse 
estandarizada la creatinina sérica, la mejor opción es utilizar los criterios de $\mathrm{MDRD}_{4}(2000)^{96}$ o Cockcroft-Gault (1976), ${ }^{101}$ ajustada al área de superficie corporal, ${ }^{1,26,96,99,100}$ considerando los factores que alteran los valores de creatinina ${ }^{15} \mathrm{e}$ implementar el S-UPCI ${ }^{26,27}$ en los exámenes de rutina, pues desde el punto de vista epidemiológico se aplica para establecer el diagnóstico de proteinuria en pacientes con enfermedad renal crónica temprana sin disminución del índice de filtrado glomerular.

\section{Financiamiento}

Los autores declaran no haber recibido financiamiento.

\section{Conflicto de interés}

Los autores declaran no tener conflicto de interés.

\section{REFERENCIAS}

1. KDOQI Clinical Practice Guidelines for Chronic Kidney Disease: Evaluation, Classification and Stratification. 2002. KDOQI Guidelines for CKD Care. The National Kidney Foundation Kidney Disease Outcomes Quality Initiative (NKF KDOQI) ${ }^{\mathrm{Tm}}$. Disponible en: http://www.kidney.org/professionals/KDOQI/guidelines_commentaries.cfm. American Journal of Kidney Diseases (AJKD)

2. Schrier RW, Coffman TM, Falk RJ, Molitoris BA, Neilson EG, editors. Schrier's Diseases of the Kidney, $9^{\text {th }}$ ed. Philadelphia: Lippincott Williams \& Wilkins, 2013;1-230.

3. World Kidney Day 2011. Disponible en: http://www.worldkidneyday.org/page/press-material

4. Myers GL, Miller WG, Coresh J, Fleming J, Greenberg N, Greene $\mathrm{T}$, et al. For the National Kidney Disease Education Program Laboratory Working Group. Recommendations for Improving Serum Creatinine Measurement: A Report from the Laboratory Working Group of the National Kidney Disease Education Program. Clinical Chemistry 2006; 52:15-18.

5. Teng HL, Yen M, Fetzer S, Sung J-M, Hung S-Y. Effects of Targeted Interventions on Lifestyle Modifications of Chronic Kidney Disease Patients: Randomized Controlled Trial. West J Nurs Res. 2013; 20(10): 1-21.

6. Hsu CC, Hwang SJ, Wen CP, Chang HY, Chen T, Shiu RS, Yang WC. High prevalence and low awareness of CKD in Taiwan:
A study on the relationship between serum creatinine and awareness from a nationally representative survey. Am J Kidney Dis 2006;48:727-738.

7. Alcázar R, Egocheaga MI, Orte L, Lobos M, González-Parra E, Álvarez-Guisasola F, Górriz JL, Navarro JF, Martín de Francisco AL. Documento de consenso SEN_semFYC sobre la enfermedad renal crónica. Nefrología 2008;28(3): 273-282.

8. Levey AS, Eckrardt KU, Tsukamoto Y, et al. Definition and classification of chronic kidney disease: a position statement from Kidney Disease Improving Global Outcomes (KDIGO). Kidney Int. 2005; 67:2089-2100.

9. Levey AS, de Jong PE, Coresh J, Nahas ME, Astor BC, et al. The definition, classification and prognosis of chronic kidney disease: a KDIGO Controversies Conference report. Kidney Int. 2011;80(1):17-28.

10. Levey AS, Coresh J, Balk E, Kausz, AT, et al. National Kidney Foundation Practice Guidelines for Chronic Kidney Disease: Evaluation, Classification, and Stratification. Ann Intern Med 2003;139: 137-147.

11. Smith HW. Comparative physiology of the kidney, in Smith HW (ed): The Kidney: Structure and Function in Health and Disease. New York: Oxford University Press, 1951;520-574.

12. Lindeman RD, Tobin J, Shock NW. Longitudinal studies on the rate of decline in renal function with age. J Am Geriatr Soc 1985;33:278-285.

13. Perrone RD, Madias NE, Levey AS. Serum creatinine as an index of renal function: New insights into old concepts. Clin Chem 1982;38:1933-1953.

14. Levey AS, Stevens LA, Schmid CH, Zhang Y, et al. The Chronic Kidney Disease Epidemiology Collaboration (CKD-EPI). A new equation to estimate glomerular filtration rate. Ann Intern Med. 2009;150(9):604-612.

15. Nyman U, Grubb A, Larson A, Hansson LO, Flodin M, et al. The revised Lund-Malmo GFR estimating equation outperforms MDRD and CKD-EPI across GFR, age and BMI intervals in a large Swedish population. Clin Chem Lab Med. 2013;52(6):1-10.

16. Frequently Asked Questions (FAQ) About GFR Estimates. National Kidney Foundation (NKF) copyright 2011. Disponible en: www.kidney.org

17. Frequently Asked Questions (FAQ) About GFR Estimates (GFRe). National Kidney Foundation (NKF) copyright 2014. Disponible en: www.kidney.org

18. National Kidney Disease Education Program (NKDEP). Laboratory Professionals: Publications and Presentations. Estimating and reporting GFR. Equations and GFR calculator. Disponible en: http://www.nkdep.nih.gov/labprofessionals/equations and GFR.htm.

19. Stevens LA, Padala S, Levey AS. Advances in glomerular filtration rate estimating equations. Curr Opin Nephrol Hypertens. 2010;19(3):298-307. 
20. Fassial A. Epidemiology and causes of end stage renal Disease. Saudi J Kidney Dis Transplant. 2005;16:277-281.

21. Troxell ML, Lanciault C. Practical applications in immunohistochemistry, evaluation of rejection and infection in organ transplantation. Arch Pathol Lab Med. 2016;140:910-925.

22. Wang $P$, Tian $Y$, Xiao $Y$, Zhang $Y$, et al. A metanephric adenoma of the kidney associated with polycythemia: A case report. Oncol Lett. 2016;11(1):352-354.

23. Dasari S, Amin MS, Kurtin PJ, Vrana JA, et al. Clinical, biopsy, and mass spectrometry characteristics of renal apolipoprotein A-IV amyloidosis. Kidney Int. 2016;90(3):658-64.

24. Escalante-Gómez C, Zeledón-Sánchez F, Ulate-Montero G. Proteinuria, fisiología y fisiopatología aplicada. Revisión. AMC 2007;49(2):83-89.

25. Keane WF, Eknoyan G. Proteinuria, albuminuria, risk, assessment, detection, elimination (PARADE): a position paper of the National Kidney Foundation. Am J Kidney Dis. 1999;33:1004-10.

26. Chadban SJ, Briganti EM, Kerr PG, Dunstan DW, et al. Prevalence of Kidney Damage in Australian Adults: The AusDiab Kidney Study. J Am Soc Nephrol. 2003;14:S131-S138.

27. Chotayaporn T, Kasitanon N, Sukitawut W, Louthrenoo W. Comparison of proteinuria determination by urine dipstick, spot urine protein creatinine index, and urine protein 24 hours in lupus patients. J Clin Rheumatol. 2011;17(3):1249.

28. Wang JM, Lin ChY, Tsai FA, Chen JY, Koa YCh. test dipstick for determination of urinary protein, creatinine and protein/ creatinine ratio. J Biomed Lab Sci. 2009;21(1):23-28.

29. Coresh J, Astor BC, Greene T, Eknoyan G, Levey AS. Prevalence of chronic kidney disease and decreased kidney function in the adult US population: Third national health and nutrition examination survey. Am J Kidney Dis 2003;41(1):1-12.

30. Warram JH, Gearin G, Laffel L, Krolewski AS. Effect of duration of type I diabetes on the prevalence of stages of diabetic nephropathy defined by urinary albumin/creatinine ratio. J Am Soc Nephrol. 1996;7:930-7.

31. Jacobs DR, Murtaugh MA, Steffes M, Yu X, Roseman J, Goetz FC. Gender- and race-specific determination of albumin excretion rate using albumin-to-creatinine ratio in single, untimed urine specimens: the Coronary Artery Risk Development in Young Adults Study. Am J Epidemiol. 2002;155:1114-9.

32. National Kidney Foundation ${ }^{\mathrm{TM}}$. Kidney disease. [En línea]. Dirección URL: <http://www.kidney.org/index.cfm>.

33. Edelstein CL. Biomarkers of acute kidney injury. Adv Chronic Kidney Dis. 2008;15(3):222-234.

34. Swedko PJ, Clark HD, Paramsothy K, Akbari A. Serum creatinine is an inadequate screening test for renal failure in elderly patients. Arch Intern Med. 2003;163:356-60.

35. Narayanan Sy Appleton HD. Creatinine: a review. Clin Chem 1980;26:1119-26.
36. Fille'e C, Vranken G, Othmane M, Philippe M, et al. Results of the recalibration of creatinine measurement with the modular Beckman Coulter Jaffe creatinine method. Clin Chem Lab Med. 2011;49(12):1987-1999.

37. Murthy K, Stevens LA, Stark PC, Levey AS. Variation in serum creatinine assay calibration: a practical application to glomerular filtration rate estimation. Kidney Int. 2005;68:1884-7.

38. Stevens LA, Levey AS. Clinical implications for estimating equations for glomerular filtration rate [Editorial]. Ann Intern Med. 2004;141:959-61.

39. Directive 98/79/EC of the European Parliament and of the Council of 27 October 1998 on in vitro diagnostic medical devices (DEPC 1998). Off J Eur Communities L. 1998;L331:1-37.

40. Panteghini M, Myers GL, Miller WG, Greenberg N. La importancia de la trazabilidad metrológica en la validez de la medición de creatinina como índice de función renal. Federación Internacional de Química Clínica y Laboratorio Clínico (IFCC), División Científica de la IFCC, Grupo de Trabajo sobre Estandarización de la Evaluación de la Tasa de Filtración Glomerular (WG-GFRA). Acta Bioquím Clín Latinoam. 2009;43(2):271-7.

41. Levey AS, Coresh J, Greene T, Marsh J, Chronic Kidney Disease Epidemiology Collaboration (CKD-EPI). Expressing the Modification of Diet in Renal Disease Study equation for estimating glomerular filtration rate with standardized serum creatinine values. Clin Chem. 2007; 53(4):766-772.

42. Flegar-Mestric Z, Perkov S, Simonovic B and Juretic D. Applicability of common reference intervals for serum creatinine concentrations to the Croatian population. Clin Chem Lab Med. 2010; 48(2): 231-235.

43. Miller W, Myers G, Ashwood E, Killeen A, et al. Creatinine measurement: state of the art in accuracy and interlaboratory harmonization. Arch Pathol Lab Med. 2005;129:297-304.

44. Miller G, Eckfeldt JA. Creatinine accuracy calibration verification participant summary. Coll Amer Pathol 2005:1-2.

45. Fischer MJ, Go A, Lora CM, Ackerson L, et al. CKD in hispanics: baseline characteristics from the cric (chronic renal insufficiency cohort) and hispanic-cric studies. Am J Kidney Dis. 2011;58(2):214-227.

46. Inker LA, Schmid CA, Tighiouart H, Eckfeld JH, et al. Estimating glomerular filtration rate from serum creatinine and cystatin C. N Engl J Med 2012;367(1):20-29.

47. Gowda S, Desai PB, Kulkarni SS, Hull VV, et al. Markers of renal function tests. N Am J Med Sci. 2010; 2(4): 170-173.28.

48. Grubb A. Non-invasive estimation of glomerular filtration rate (GFR). The Lund model: Simultaneous use of cystatin $C$ - and creatinine-based GFR-prediction equations, clinical data and an internal quality check. Scand J Clin Lab Invest. 2010; 70:65-70.

49. Manetti L, Pardini E, Genovesi M, Campomori A, et al. Thyroid function differently affects serum cystatin 
C and creatinine concentrations. J Endocrinol Invest. 2005;28:346-349.

50. Risch L, Herklotz R, Blumberg A, Huber AR. Effects of glucocorticoid immunosuppression on serum cystatin $C$ concentrations in renal transplant patients. Clin Chem. 2001;47:2055-2059.

51. Risch L y Huber AR. Glucocorticoids and increased serum cystatin C concentrations. Clin Chim Acta. 2002;320:133134.

52. Knight EL, Verhave JC, Spiegelman D, Hiellege HL, et al. Factors influencing serum cystatin $\mathrm{C}$ levels other than renal function and the impact on renal function measurement. Kidney Int. 2004;65:1416-1421.

53. Köttgen A, Selvin E, Stevens LA, Levey AS, Van Lente F, CoreshJ. Serum cystatin $C$ in the United States: The Third NationalHealth and Nutrition Examination Survey (NHANES III). Am JKidney Dis. 2008;51:385-94.

54. Fernández-García M, Coll E, Ventura-Pedret $\mathrm{S}$, BermudoGuitarte $C$, et al. Cistatina $C$ en la evaluación de la función renal. Rev Lab Clin. 2011;4(1):50-62.

55. Priem $F$, Althaus $H$, Jung $K$, Sinha $P$. b-Trace protein is not better than cystatin $\mathrm{C}$ as an indicator of reduced glomerular filtration rate. Clin Chem. 2001;47:2181.

56. Hayden MR y Tyagi SC. Uric acid: A new look at an old risk marker for cardiovascular disease, metabolic syndrome, and type 2 diabetes mellitus: The urate redox shuttle. Nutr Metab. 2004;1:1-10.

57. Nakagawa T, Kang DH, Feig D, Sánchez-Lozada LG, et al. Unearthing uric acid: An ancient factor with recently found significance in renal and cardiovascular diseases. Kidney Int 2006;69:1722-1725.

58. Ryoo JH, Choi JM, Oh ChM, Kim MG. The association between uric acid and chronic kidney disease in korean men: A 4-year follow-up study. Korean Med Sci 2013;28:855-860.

59. Khosla U, Zharikov S, Finch J, Nakagawa T, et al. Hyperuricemia induces endothelial dysfunction. Kidney Int 2005;67:1739-1742.

60. Zoccali C, Maio R, Mallamaci F, Sesti G, Perticone F. Uric acid and endothelial dysfunction in essential hypertension. J Am Soc Nephrol 2006;17:1466-71.

61. Sanchez-Lozada LG, Tapia E, Santamaria J, Ávila-Casado $C$, et al. Mild hyperuricemia induces vasoconstriction and maintains glomerular hypertension in normal and remnant kidney rats. Kidney Int 2005;67:237-47.

62. James S, Mitchel G. Physiology and disorder of water electrolytes and acid base metabolism. In: Carl AB, Edward $R$, David $E$, editors.Tietz Textbook of clinical chemistry and molecular diagnostics. $4^{\text {th }}$ Ed. New Delhi: Elsevier Inc, 2006;1747-1776

63. Drechsler C, Kollerits B, Meinitzer A, März W, et al. The MMKD Study Group. Homoarginine and Progression of Chronic Kidney Disease: Results from the Mild to Moderate Kidney Disease Study. PLoS One 2013;8(5):e63560.
64. Hasegawa H, Nagano N, Urakawa I, Yamazaki Y, et al. Direct evidence for a causative role of FGF23 in the abnormal renal phosphate handling and vitamin D metabolism in rats with early-stage chronic kidney disease. Kidney Int. 2010;78:975-980.

65. Isakova T, Wahl P, Vargas GS, Gutierrez OM, et al. Fibroblast growth factor 23 is elevated before parathyroid hormone and phosphate in chronic kidney disease. Kidney Int. 2011;79:1370-1378.

66. Evenpoel P, Myles W. A balanced view of calcium and phosphate homeostasis in chronic kidney disease. Kidney Int. 2013;83(5):789-791.

67. Negri AL. The klotho gene: a gene predominantly expressed in the kidney is a fundamental regulator of aging and calcium/phosphorus metabolism. J Nephrol. 2005;18(6):654-8.

68. Parikh CR, Mishra J, Thiessen-Philbrook $\mathrm{H}$, et al. Urinary IL-18 is an early predictive biomarker of acute kidney injury after cardiac surgery. Kidney Int. 2006;70:199-203.

69. Faggioni R, Jones-Carson J, Reed DA, et al. Leptin-deficient (ob/ob) mice are protected from T cell-mediated hepatotoxicity: Role of tumor necrosis factor alpha and IL-18. Proc Natl Acad Sci USA. 2000;97:2367-2372.

70. Faggioni R, Cattley RC, Guo J, et al. IL-18-binding protein protects against lipopolysaccharide induced lethality and prevents the development of Fas/Fas ligand-mediated models of liver disease in mice. J Immunol. 2001;167:59135920.

71. Fiorucci S, Santucci L, Antonelli E, et al. NO-aspirin protects from $T$ cell-mediated liver injury by inhibiting caspasedependent processing of Th1-like cytokines. Gastroenterology. 2000;118:404-421.

72. Schmidt-Ott KM, Mori K, Li JY, et al. Dual action of neutrophil gelatinase-associated lipocalin. J Am Soc Nephrol. 2007;18:407-413.

73. Bachorzewska-Gajewska H, Malyszko J, Sitniewska E, Malyszko JS, Dobrzycki S. Neutrophil-gelatinase-associated lipocalin and renal function after percutaneous coronary interventions. Am J Nephrol. 2006;26(3):287-292.

74. Zappitelli M, Washburn KK, Arikan AA, Lofitis L, et al. Urine neutrophil gelatinase-associated lipocalin is an early marker of acute kidney injury in critically ill children: A prospective cohort study. Crit Care. 2007;11:R84.

75. Bolignano D, Coppolino G, Campo S, et al. Neutrophil gelatinase-associated lipocalin in patients with autosomal-dominant polycystic kidney disease. Am J Nephrol. 2007:27:373-378.

76. Trachtman $\mathrm{H}, \mathrm{Christen} \mathrm{E}, \mathrm{Cnaan} \mathrm{A}$, et al. Investigators of the HUS-SYNSORB Pk Multicenter Clinical Trial: Urinary neutrophil gelatinase-associated lipocalcin in D+HUS: A novel marker of renal injury. Pediatr Nephrol. 2006;21:989-994.

77. Suzuki M, Wiers KM, Klein-Gitelman MS, et al. Neutrophil gelatinase-associated lipocalin as a biomarker of disease 
López-Heydeck SM y col. Diagnóstico temprano de insuficiencia renal crónica

activity in lupus nephritis. Pediatr Nephrol. 2008;23:403412.

78. Han WK, Bailly V, Abichandani R, Thadhani R, Bonventre $\mathrm{JV}$, et al. Kidney injury molecule-1 (KIM-1): A novel biomarker for human renal proximal tubule injury. Kidney Int. 2002;62:237-244.

79. Ichimura T, Bonventre JV, Bailly V, Wei H, Hession CA, Cate RL, Sanicola M. Kidney injury molecule-1 (KIM-1), a putative epithelial cell adhesion molecule containing a novel immunoglobulin domain, is up-regulated in renal cells after injury. J Biol Chem. 1998;273(7):4135-4142.

80. Perazzi B y Angerosa M. Creatinina en sangre: calidad analítica e influencia en la estimación del índice de filtrado glomerular. Acta Bioquím Clin Latinoam. 2011;45(2): 265-72.

81. Levey AS, Bosch JP, Lewis JB, Greene T, Rogers N, Roth D. A more accurate method to estimate glomerular filtration rate from serum creatinine: a new prediction equation. Ann Intern Med. 1999;130:461-70.

82. Farías R. Tasa de filtración glomerular mediante depuración de creatinina y fórmula MDRD en la enfermedad renal crónica. Salus 2012;16(1):5-12.

83. Coresh J, Selvin E, Stevens LA, Manzi J, et al. Prevalence of chronic kidney disease in the United States. JAMA 2007;298(17):2038-2047.

84. Levey AS, Coresh J, Greene T, Stevens LA, et al. Using standardized serum creatinine values in the Modification of Diet in Renal Disease Study equation for estimating glomerular filtration rate. Ann Intern Med. 2006;145(4):247-254.

85. Sterner G, Frennby B, Hultberg B, Almen T. Iohexol clearance for GFR -determination in renal failure- single or multiple plasma sampling?. Nephrol Dial Transplant 1996;11:521-525.

86. Schwartz GJ, Schneider MJ, Maier PS, Moxey-Mims M, Dharnidharka VR, Warady B, Furth SL, Muñoz A. Improved equations estimating GFR in children with chronic kidney disease using an immunonephelometric determination of cystatin C. Kidney Int. 2012;82(4):445-453.

87. DuBois D y DuBois EF. A formula to estimate the approximate surface area if height and weight be known. Arch Intern Med. 1916; 17:863-871.

88. Haycock GB, Schwartz GJ, Wisotsky DH. Geometric method for measuring body surface area: a height-weight formula validated in infants, children, and adults. J Pediatr. 1978; 93:62-66. [PubMed: 650346]

89. Krutzen E, Back SE, Nilsson-Ehle I, Nilsson-Ehle P. Plasma clearance of a new contrast agent, iohexol: a method for the assessment of glomerular filtration rate. J Lab Clin Med. 1984; 104: 955-961.

90. O'Reilly PH, Brooman PJC, Martin PJ, Pollard A, Farah NB, Mason GC. Accuracy and reproducibility of a new contrast clearance method for the determination of glomerular filtration rate. Br Med J. 1986; 293: 234-236.

91. Lewis R, Kerr N, Van Buren C, Lowry P, Sandier C. Comparative evaluation of urographic contrast media, inulin and
99mTc-DTPA clearance methods for determination of GFR. Transplantation 1989; 48: 790-796.

92. Effersoe T, Rosenkilde P, Groth S, Jensen LI, Golman K. Measurement of renal function with iohexol: a comparison of iohexol, 99mTc-DTPA, and 51Cr-EDTA clearance. Invest Radiol. 1990; 25: 778-782.

93. Brown SCW y O'Reilly PH. lohexol clearance for the determination of glomerular filtration rate in clinical practice: Evidence for a new gold standard. J Urol. 1991; 146: 675-679.

94. Stake G, Monn E, Rootwelt K, Gronberg T, Monclair T. Glomerular filtration rate estimated by $\mathrm{X}$-ray fluorescence technique in children; comparison between the plasma clearance of 99mTc-DTPA and iohexol after intravenous urography. Scand J Clin Lab Invest. 1990; 50: 161-167.

95. Shafi T, Matsushita K, Selvin E, Sang Y, Astor BC, Inker LA y Coresh J. Comparing the association of GFR estimated by the CKD-EPI and MDRD study equations and mortality: the third national health and nutrition examination survey (NHANES III). BMC Nephrol. 2012; 13: 42. doi: 10.1186/1471-2369-13-42

96. Levey AS, Greene T, Kusek JW, Beck GJ, Group MS. A simplified equation to predict glomerular filtration rate from serum creatinine. J Am Soc Nephrol. 2000; 11: 155A (A0828).

97. Matsushita K, Mahmoodi BK, Woodward M, Emberson JR, Jafar TJ, Jee S-J, Polkinghorne KR, Shankar A, Smith DH, Tonelli M, Warnock DG, Wen Ch-P, Coresh J, Gansevoort RT, Hemmelgarn BR, Levey AS. Comparison of Risk Prediction Using the CKD-EPI Equation and the MDRD Study Equation for Estimated Glomerular Filtration Rate. JAMA 2012; 307(18): 1941-1951.

98. Arreola-Guerra JM, Rincón-Pedrero R, Cruz-Rivera C, Belmont-Pérez T, Correa-Rotter R, Niño-Cruz JA. Performance of MDRD-IDMS and CKD-EPI equations in Mexican individuals with normal renal function. Nefrologia 2014; 34(5):591-8. doi:10.3265/Nefrologia. pre2014.Jun. 12538

99. Sandoval-Arriaga A. Estructura corporal y diferenciación social: un estudio en adultos jóvenes de la ciudad de México. Universidad Nacional Autónoma de México; Instituto de Investigaciones Antropológicas 1985; 241 p.

100. Grubb A. Non-invasive estimation of glomerular filtration rate (GFR). The Lund model: Simultaneous use of cystatin $\mathrm{C}$ - and creatinine-based GFR-prediction equations, clinical data and an internal quality check. Scand J Clin Lab Invest, 2010; 70:65-70. [PubMed: 20170415]

101. Cockcroft DW y Gault MH: Prediction of creatinine clearance from serum creatinine. Nephron 1976; 16: 31-41.

102. Jones GRD y Lim E. The National Kidney Foundation guideline on estimation of the glomerular filtration rate. Clin Biochem Rev. 2003; 24:95-98.

103. Teruel JL, Sabater J, Galeano C, Rivera M, Merino JL, Fernández-Lucas $M$, Marcén $R$ y Ortuño J. La ecuación de Cockroft-Gault es preferible a la ecuación MDRD para 
medir el filtrado glomerular en la insuficiencia renal crónica avanzada. Nefrología 2007; 27(3): 313-319.

104. Rostoker G, Andrivet P, Pham I, Griuncelli M, Adnot S. A modified Cockcroft-Gault formula taking into account the body surface area gives a more accurate estimation, of the glomerular filtration rate. J Nephrol. 2007; 20:576-585.

105. Rostoker G, Andrivet P, Pham I, Griuncelli M y Adnot S. Accuracy and limitations of equations for predicting the glomerular filtration rate during follow-up of patients with non-diabetic nephropathies. BMC Nephrol. 2009; 10: 16.

106. Schwartz GJ, Haycock GB, Edelmann CM Jr, Spitzer A. A simple estimate of glomerular filtration rate in children derived from body length and plasma creatinine. Pediatrics 1976; 58: 259-263.

107. Counahan R, Chantler C, Ghazali S, Kirkwood B, Rose F, Barratt TM: Estimation of glomerular filtration rate from plasma creatinine concentration in children. Arch Intern Med. 1976 51: 875-878.

108. Amato D, Álvarez-Aguilar C, Castañeda-Limones R, Rodríguez E, Ávila-Díaz M, Arreola F, Gómez A, Ballesteros Hiriam, Becerril R, Paniagua R. Prevalence of chronic Kidney disease in an urban Mexican Population. Kidney Internarnational 2005; 68 (97):S11-S17.

109. Méndez-Durán A, Méndez-Bueno JF, Tapia-Yáñez T, Muñoz Montes A, Aguilar-Sánchez L. Epidemiología de la insuficiencia renal crónica en México. Dial Traspl. 2010; 31(1): 7-11.
110. Instituto Nacional de Estadísticas y Geografía (INEGI) México. Mujeres y hombres en México 2011. Disponible en: http://www.inegi.org.mx/prod_serv/contenidos/espanol/bvinegi/productos/integracion/sociodemografico/ mujeresyhombres/2011/myh2011.pdf

111. García-García G, Monteon-Ramos JF, García-Bejarano H, Gómez-Navarro B, Hernández-Reyes I, Lomelí AM, Palomeque M, Cortés-Sanabria L, Breien-Alcaraz H, RuizMorales N. Renal replacement therapy among disventaged populations in Mexico: A report from the Jalisco Dialysis and Transplant Registry (REDTJAL). Kidney International 2005; 68: S58-S61; doi: 10.1111/j.1523-1755.2005.09710.x

112. United States Renal Data System: Excerpts from the USRDS 2009 Annual Data Report: Atlas of End-Stage Renal Disease in the United States. International Comparisons. Am J Kidney Dis. 2010; 55(1 Suppl 1): A6-A7S173-S180.

113. Guía de Práctica Clínica, Prevención, Diagnóstico y Tratamiento de la Enfermedad Renal Crónica Temprana (GPCPDTERCT); México, Secretaría de Salud, 2009.

114. Medina-Escobedo M, Sansores-España D, Villanueva-Jorge S. Función renal en un grupo marginado de la población. Rev Med Inst Mex Seguro Soc. 2014; 52(2):156-61.

115. Soto-Domínguez FE, Pozos-Pérez ME, Barrientos-Guerrero CE, Torres-Fermán IA, Beltrán-Guzmán FJ. Detección oportuna de insuficiencia renal oculta en pacientes adultos en atención primaria a la salud. Rev Med UV, 2009; 15(3). Disponible en: http://www.medigraphic.com/pdfs/veracruzana/muv-2009/muv092d.pdf

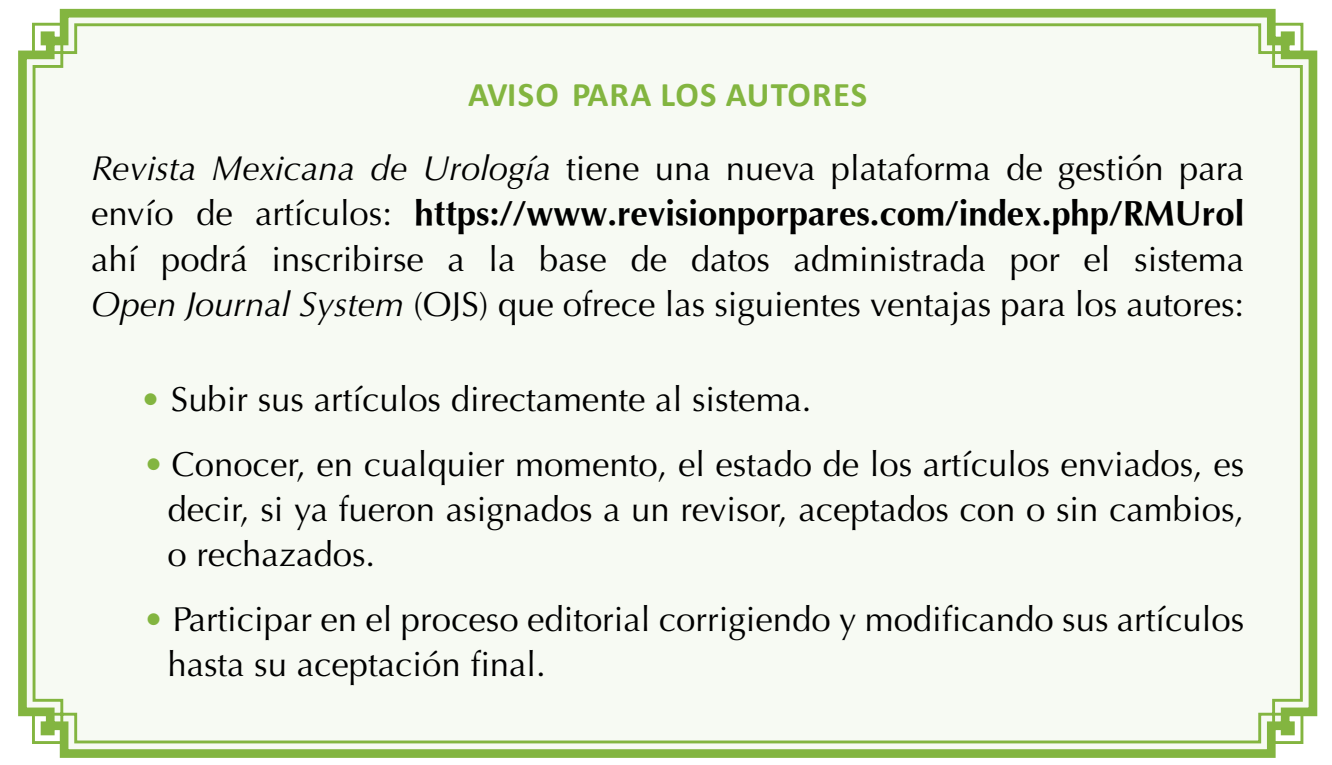

